\title{
A computer-based approach for analyzing consumer demands in electronic word-of-mouth
}

\author{
Chung-Yi Lin ${ }^{1} \cdot$ Shu-Yi Liaw ${ }^{2}$ Chao-Chun Chen ${ }^{1} \cdot$ Mao-Yuan Pai ${ }^{1} \cdot$ Yuh-Min Chen ${ }^{1}$
}

Received: 19 November 2015 / Accepted: 15 June 2017 / Published online: 2 August 2017

(C) The Author(s) 2017. This article is an open access publication

\begin{abstract}
Consumer opinions are one of the most valuable assets that enterprises have, and thus questionnaires are often employed to investigate the views of consumers. However, this approach requires a large amount of human labor and time, and, most importantly, it cannot automatically find out consumers' needs. However, many consumers now share their appraisals of products or services through electronic word-of-mouth (eWOM). Since these usually reflect consumer needs, and thus their demands, collecting and analyzing eWOM data has become a key task for many businesses. Nonetheless, current eWOM-related research focuses on its transmission, influence, issues, and marketing, and there seem to be very few studies that apply eWOM to develop consumer needs analysis systems. In order to effectively collect and analyze eWOM data, this study proposes a computer-based approach for analyzing consumer demands. The approach utilizes sentiment analysis to develop extraction
\end{abstract}

Responsible Editors: Doug Vogel and Judith Gebauer

Yuh-Min Chen

ymchen@mail.ncku.edu.tw

Chung-Yi Lin

P98991109@gmail.com

Shu-Yi Liaw

syliaw@mail.npust.edu.tw

Chao-Chun Chen

chaochun@mail.ncku.edu.tw

Mao-Yuan Pai

maoyuanpai@gmail.com

1 Institute of Manufacturing Information and Systems, National Cheng Kung University, Tainan, Taiwan, Republic of China

2 Department of Business Administration and Director of Computing Center, National Pingtung University of Science and Technology, Neipu, Pingtung County, Taiwan, Republic of China methods for use with eWOM appraisals. It thus uses eWOM appraisals to find out consumer demands. This work integrates eWOM with information technology to develop an approach to computerize consumer needs analysis. It is expected that the results will help enterprises to improve the quality of their products and market competitiveness.

Keywords Electronic Word-of-Mouth (eWOM) $\cdot$ Knowledge management $\cdot$ Consumer demands $\cdot$ Sentiment analysis

JEL Classification C88 Other Computer Software

\section{Introduction}

In this service economy era, enterprises' primary goals include rapid responses to consumer requirements, shortening the time needed to launch new products or services, and improving the quality of their products (Choi et al. 2011; Chen and Cheng 2009; Walstad and Rebeck 2002). To meet these goals, more and more companies are putting efforts into discovering consumer demands with regard to their brands, products, and services. This information can then be used as a reference when designing new products or making innovations. Therefore, the efficient gathering and analysis of consumer demands can help companies to remain competitive (Kuo et al. 2009; Bei and Shang 2006; Chen et al. 2016).

With the development of new technologies, a growing number of consumers now post their opinions about products or services on blogs, web forums, and bulletin board systems (BBS), as well as in e-mails. This phenomenon is called, "electronic word-of-mouth" (eWOM) or "online word-ofmouth" (Hennig-Thurau and Walsh 2003, Pai et al. 2013a). eWOM is essentially consumer product or service appraisals, and thus also include important consumer demands. In order to 
understand consumer demands, enterprises are therefore investing a substantial amount of money in the collection and analysis of eWOM content. However, the tremendous amount of such information that is available online often overwhelms these collection and analysis efforts, and results in information overload (Park and Lee 2009).

A number of studies have undertaken examinations of the transmission (Chen et al. 2014; Erkan and Evans 2016), influence (Chu and Sung 2015; Kim and Johnson 2016; Wu and Lin 2017), and marketing (Nieto et al. 2014) of eWOM. Currently, however, there are very few eWOM-related studies that discuss the analysis of consumer demands through computerized eWOM. The most similar work to the current on is Archak et al. (2011), which defined the characteristics of a product and then brought up specific descriptions of the product from the eWOM content. The characteristics were then used to find consumers' needs. Appraisal words are the sentiments, opinions or thoughts consumers have toward products. As a result, Archak et al. (2011) used POS (part of speech) tagging to find out the nouns from the online appraisals, which were then used as the appraisal words. However, not every noun could express consumers' sentiments, opinions or thoughts. Besides, the analytical results of his research tended to be more subjective, because it required much labor used to cross reference the eWOM data, noun and appraisal words. Since most appraisals are done with sentiment words (Feng et al. 2011; Söderlund and Rosengren 2007), by applying emotion analysis techniques to eWOM, it is expected to that it will be possible to find the nouns related to sentiments. Instead of carrying out the analysis through traditional labor-intensive approaches, the current study applied many mature information technologies and method to do a consumer needs analysis using the eWOM data, nouns and appraisal words. Therefore, the analytical results of this study tend to be more objective. As such, this study is different from Archak et al. (2011) with regard to the data it analyzes.

By using appraisal words, it is expected that it will be possible to better understand consumers' preferences and get more comprehensive results. However, few studies have been conducted to investigate methods for the semantic analysis of eWOM. One of the advantages of analyzing eWOM content is that it directly reveals consumer opinions, which can enable enterprises to monitor market changes in real time. Nevertheless, the difficulty of analyzing eWOM lies in the complexity of the semantic content. Since consumers often use "text speak" to post their opinions online, and because there are no standard writing formats and unified descriptive words for online reviews (Pai et al. 2013a), the difficulty of analysis is increased. These problems also prevent computer programs from analyzing the text, and thus extracting the meanings of these terms is even more difficult. Despite the abovementioned difficulties, a number of enterprises continuously collect and analyze eWOM, aiming to find out consumer demands. Nevertheless, traditional eWOM data collection wastes a lot of time, which usually results in delayed reactions to the market. Therefore, this study proposes a computer-based approach for the analysis of consumer demands. In order to develop a computerized eWOM analysis system, eWOM collection programs are employed to replace human labor in terms of searching and collecting eWOM content. The process of appraisal extraction and appraisal word classification is thus computerized to replace human labor. This use of information technology is expected to boost the speed of eWOM content analysis. In addition, traditional research into business administration or information technology puts emphasis on issues such as the spread, decision-making, and market-influence of eWOM. In contrast, information technology is rarely employed for the collection and analysis of eWOM. Therefore, employing information technology to analyze eWOM is an issue that deserves more attention. This study does not develop new algorithm or techniques for eWOM, but it applies welldeveloped information technology to develop a new application, and thus can be easily adopted by enterprises, and this indicated the value of the current work.

In summary, this study proposes a computer-based approach for the analysis of consumer demands. However, before constructing a complete system, a conceptual model or theory is suggested to be used as the foundation for developing it. As such, the system design is based on a review of the literature and is more reasonable than would otherwise be the case (Chen and Chen 2012; Chen 2011; Pai et al. 2013a; Pai et al. 2013b). Specifically, this study has the following objectives: (i) constructing a consumer demands analysis model in eWOM; (ii) designing a consumer demands analysis procedure; and (iii) developing a system for analyzing consumer demands. Finally, this study carries out an empirical test to validate the proposed method.

\section{Consumer demands analysis model using eWOM}

In order to analyze consumer demands efficiently, this section reviews traditional approaches for analyzing them and investigates the problems that they have. Approaches to the analysis of the relationship between appraisal words and consumer demands are also discussed. Finally, based on this review of the literature, details of the design of the consumer demand analysis model using eWOM are presented.

\section{Review of traditional approaches for analyzing consumer demands}

In order to gain the satisfaction and support of customers, businesses have long developed their products and services based on consumer opinions (Bai et al. 2008; Deng et al. 2010; JiménezJiménez and Cegarra-Navarro 2007; Kim et al. 2004), with many enterprises and scholars using questionnaires to identify key consumer demands. The various methods that are used in the studies examined in this literature review to investigate consumer 
Fig. 1 Traditional approaches for analyzing consumer demands

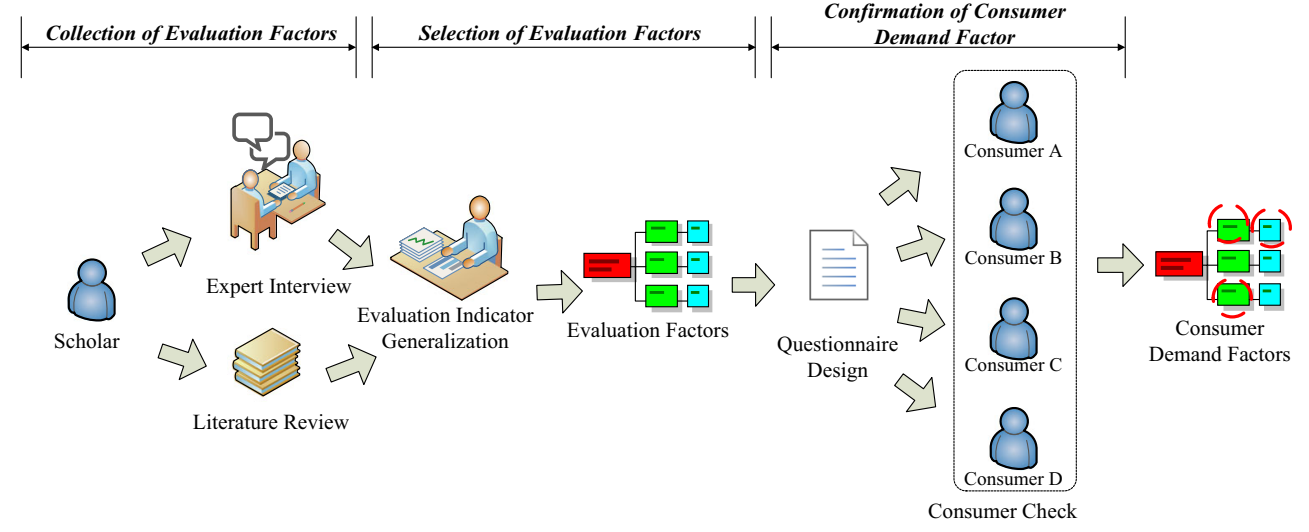

demands are shown in Fig. 1 (Kwon 2005; Grigoroudis and Siskos 2004; Park 2004), and described below.

Collection of evaluation factors Very often a researcher first collects the critical factors that influence purchasing decisions by employing two methods: First, experts are interviewed to identify evaluation factors. Second, a literature review is undertaken to identify evaluation factors. Nonetheless, these two data collection methods have their limitations. Insufficient information from the experts may jeopardize the reliability of the study, and an incomprehensive literature review can also hinder reliability.

Selection of evaluation factors After extensive data collection, the evaluation factors are organized and classified. This requires researchers to sort the data, and repetitions of similar evaluation factors are eliminated. However, this process is time-consuming and laborious.

Confirmation of consumer demand factors The generated evaluation factors are subsequently used to design a questionnaire. By this process, the exact consumer demand factors can be identified.

The procedures outlined above require a considerable amount of work to filter and organize the collected data. However, using a computer-based approach it is possible to use automation to reduce the complexity of this process and avoid errors, and thus improve the accuracy of consumer demands analysis.

\section{Analysis of the relationship between appraisal words and consumer demands}

To attain effective analysis of consumer demands from eWOM using computers, this research focuses on examining eWOM to gain insights. eWOM comes from consumers' actual encounters with the focal product or service, and includes valuable information on key consumer demands (Pai et al. 2013a). Consumers share their demands in eWOM using appraisal words when they have positive or negative experiences with a product or service. On the other hand, when the experience is not significantly good or bad, consumers tend not to use appraisal words to express their demands. That said, in general appraisal word indicate consumer demands. Pai et al. (2013b) carried out a SWOT analysis on products or services by examining positive or negative appraisals. Enterprises can then use the results of the SWOT analysis to improve their products or services. SWOT is a tool for market analysis (Kotler and fox 1995), and this is done to better understand consumer needs and demands from the mass market. As a result, we can figure out consumer needs from eWOM appraisals (Pai et al. 2013b).

There are many studies that use keywords to obtain predictions of the economy or consumer decision-making. For example, Choi and Varian (2012) utilized Google Trends to carry out keyword analysis. The frequencies of the analysis were used as the near-term values of economic indicators. Moreover, Preis et al. (2013) found that the frequency of keywords could be used as "early warning signs". When a keyword is searched for more frequently, this may imply that it interests a lot of people. The frequencies of keywords can thus be used to assist investment decision-making. Similarly, when there are a lot of consumers who use a specific appraisal word to express their opinions about a product, the specific appraisal words used can present the needs and expectations of consumers. When the frequency of appraisal words rises or drops dramatically, then this can be seen as an early warning sign that businesses should pay attention to.

Generally speaking, the amount of appraisal a product or service receives tends to be steady, and a sudden shift in this would indicate a change in consumer demands. For example, certain aspects of a product would attract consumers' attention, thus leading to more appraisals, or another product's lack of features would not receive much interest, thus leading to a fall in the desire to discuss it. Therefore, when there is a significant change in the number of appraisals, it is likely that consumers' demands have altered. A company's marketing department and management could utilize this as a basis for determining consumer demands, and find out the reasons behind such changes. Statistically, the number of eWOM appraisal words is increasing every day. The sample of appraisal words collected in this study is $n \geq 30$, and thus a large sample pool. Based on central limit theorem, no matter what kind of distribution a population has, the sampling distribution approaches a normal one. Therefore, this 
research assumes that eWOM appraisal words are normally distributed, and under a $95 \%$ confidence interval the frequencies of eWOM appraisal words would fall into the range of $[\mu+2 \sigma, \mu-$ $2 \sigma]$. When the number of appraisal words exceeds the $95 \%$ confidence interval range, it means there is a significant change in the number of appraisals.

Frequencies have been used in many studies as an indicator of future trends. For instance, Google Trends uses the frequency of searches for keywords to determine trends in various related areas. Fig 2 shows a progression graph for the keyword "KFC" (Kentucky Fried Chicken) between 2005 and 2010, and the letters $\mathrm{A}$ to $\mathrm{M}$ indicate different events during this period. As shown by the graph, the number of searches for KFC changes with each event, and this is especially true for events $\mathrm{J}$ and $\mathrm{K}$. It could then be inferred that these two events attracted the most attention from consumers online. In this research, we focus on understanding consumer demands using appraisal words, and the consumers' perceptions are shown by significant upswings or downswings in the use of these. In short, the frequencies of the appearance of appraisal words are used as indicators for identifying consumer demands.

Currently, many enterprises utilize eWOM to understand the competitive situations of their markets. They also use eWOM to understand the needs of consumers. Based on their understanding of consumer needs, enterprises can then take actions to cater to these, such as by making innovations or improving their products (Peter 1999). This also indicates that eWOM contains information about consumer needs. eWOM is thus an intellectual tool that is valued by enterprises, and many enterprises have started to collect and analyze eWOM to understand the needs of consumers. Therefore, we can view the appraisals or opinions of eWOM as consumer needs. A lot of appraisals related to products or services are expressed by using sentiment words (Söderlund and Rosengren 2007). Researchers such as Pai et al. (2013a) thus used sentiment analysis to extract information. The advantage of using information technology to process eWOM is that it can obtain eWOM-related information automatically. Businesses can then follow consumers' opinions or appraisals and respond to them more efficiently. Current information technology is able to collect and analyze eWOM automatically, so making it easier to understand consumer needs.

To effectively understand the relationship between appraisal words and consumer demands, we use one case for the purpose of demonstration. For example, eWOM authors use appraisal words, such as "delicious," "smells good," and "not bad," to express their feelings about a food. However, eWOM authors' use of such words varies due to their different demographic backgrounds, such as environment, education, and age. Different appraisal words from a variety of authors can cause difficulties in computerized content analysis. To clarify this information, appraisal words have been organized based on the following characteristics.

Synonyms These are appraisal words that describe similar consumer demand factors. For example, for the consumer demand factor "flavor," "concentrated" is synonymous with "nice-smelling," while for the consumer demand factor "environment," "beautiful" is synonymous with "clean" (Fig. 3).

Antonyms Appraisal words that describe similar consumer demand factors but are opposite in meaning. For example, the appraisal words "nice-smelling" and "bad-smelling" express positive and negative flavor, respectively. Therefore, "nice-smelling" and "bad-smelling" are antonyms that describe the same consumer demand factor "flavor" (Fig. 4).

Multi-relational Appraisal words can sometimes be used to describe multiple consumer demand factors. For example, "not bad" and "very good" describe both the "flavor" and "environment" consumer demands factors.

The discussion above demonstrates that appraisal words encompass the concepts that consumers wish to express, which can represent key consumer demands. The present study classified appraisal words into categories based on their characteristics, as shown in Table 1.

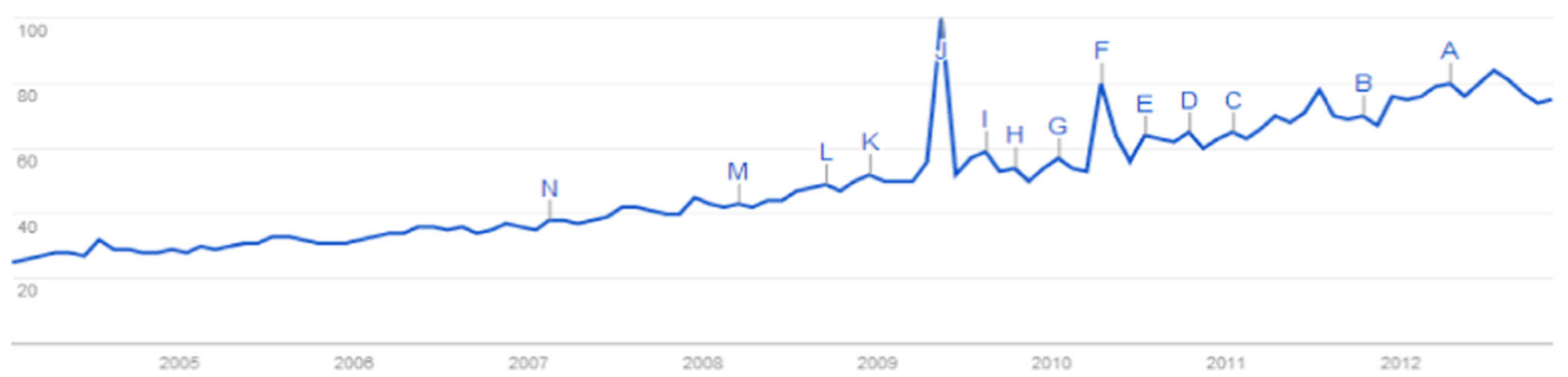

Fig. 2 Keyword trends for "KFC" 


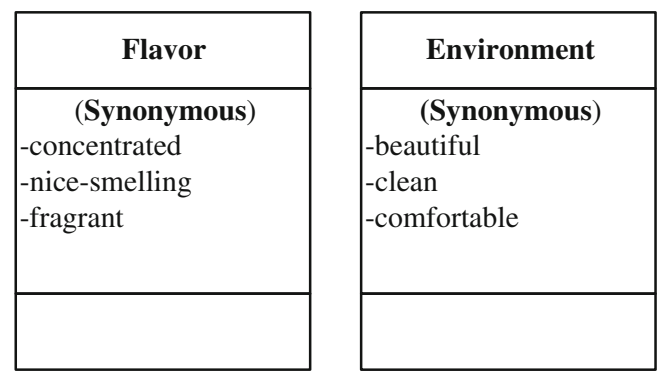

Fig. 3 Examples of synonymous appraisal words

\section{Design of consumer demand analysis model in eWOM}

Based on the analysis of the relationships between appraisal words and consumer demands, this study designed a consumer demands analysis model. This may help enterprises to have a better understanding of consumer demands, as shown in Fig. 5. In order to solidify the theoretical foundation of the consumer demands analysis model, this study applied the eWOM management framework for service experience (Pai et al. 2013a), and DIKW hierarchy (data, information, knowledge and wisdom hierarchy) (Rowley 2007) as the framework for designing the consumer demands analysis model. The consumer demands analysis model mainly consists of eWOM collection, appraisal extraction, and appraisal word classification, as is explained in more detail below:

eWOM collection eWOM belongs to the data level in DIKW hierarchy. The sources of eWOM were from blogs, web forums, and bulletin board systems (BBS). In order to effectively collect eWOM, this study used eWOM management framework for service experience (Pai et al. 2013a) as the framework. The consumer demands analysis model was used to design the eWOM collection stage, and the eWOM content was collected mainly from blogs, web forums, and bulletin board systems (BBS).

Appraisal extraction eWOM includes opinions and appraisal from consumers. The consumers often use appraisal words to express their opinions and thoughts. Therefore, the appraisals are important information for

\begin{tabular}{|l|l|l|}
\hline \multicolumn{1}{|c|}{$\begin{array}{c}\text { Flavor } \\
\text { (Positive Appraisal) }\end{array}$} & \multicolumn{1}{c|}{$\begin{array}{c}\text { Flavor } \\
\text { (Negative Appraisal) }\end{array}$} \\
\hline $\begin{array}{ll}\text {-concentrated } \\
\text {-nice-smelling } \\
\text {-fragrant }\end{array}$ & & $\begin{array}{l}\text {-diluted } \\
\text {-bad-smelling } \\
\text {-stinky }\end{array}$ \\
\hline & \\
\hline
\end{tabular}

Fig. 4 Examples of antonymous appraisal words
eWOM data. This study applied the theory of DIKW hierarchy to extract these, with the appraisal words defined at the information level. In addition, we used the eWOM management framework for service experience (Pai et al. 2013a) to design the appraisal extraction stage in the consumer demands analysis model. The aim here is to find out important appraisal information from eWOM data.

Appraisal word classification Classification is a common tool that is often used in knowledge management. However, each appraisal word is an independent piece of information. In order to construct the relationships among appraisal words, we applied an appraisal classification to produce the knowledge context between appraisal words. Therefore, based on DIKW hierarchy theory, this study defined appraisal knowledge at the knowledge level. In order to solidify its theoretical foundations, this study used the eWOM management framework for service experience (Pai et al. 2013a). We designed the appraisal word classification stage in the consumer demands analysis model. The primary purpose of this is to classify and categorize appraisal words. After this, the knowledge context of appraisal words is produced.

Consumer demand identification Wisdom uses knowledge as its foundation. Through classifying, organizing, and analyzing this, new applications or values are found. Nonetheless, eWOM does not generate wisdom, but only business intelligence (BI). BI is a combination of statistics about business operations and analytical tools. It mainly provides information concerning market trends so that enterprises can carry out business planning or decision making (Watson and Wixom 2007), Hence, finding out consumer demands through eWOM can be said to be a kind of BI. BI and wisdom belong to advanced knowledge, that is, the wisdom level in the DIKW hierarchy. In order to solidify the theoretical foundation of the consumer demands analysis model, the researchers of this study referred to the eWOM management framework for service experience (Pai et al., 2013) in the designing consumer demand identification stage for the consumer demands analysis model. The primary function was to analyze appraisal knowledge so that the analytical results could serve as the basis to identify and filter consumer needs.

\section{Methods and technologies}

This study integrated the approaches shown in Fig. 5 into the design of procedure for analyzing consumer demands in eWOM. This procedure includes eWOM collection, appraisal extraction, appraisal word classification, and consumer demands identification. 
Table 1 Definitions of appraisal word characteristics

\begin{tabular}{lll}
\hline Appraisal word characteristics & Definition & Classification \\
\hline Synonyms & Appraisal words that describe similar consumer demand factors & $\begin{array}{c}\text { Synonyms that describe the same consumer } \\
\text { demand factor } \\
\text { Antonyms that describe the same consumer } \\
\text { demand factor } \\
\text { Antonyms }\end{array}$ \\
Multi-relational & $\begin{array}{c}\text { Appraisal words that describe similar consumer demand factors, } \\
\text { but are opposite in meaning } \\
\text { Appraisal words that can be used to describe multiple } \\
\text { consumer demand factors }\end{array}$ & $\begin{array}{c}\text { Experts decide the classification of words } \\
\end{array}$ \\
\hline
\end{tabular}

\section{Procedure for analyzing consumer demands in eWOM}

Based on the design of the consumer demands analysis model in eWOM in Fig. 5, this study develops procedures for consumer demands analysis. In this way, the enterprises may be able to better understand consumer demands, as shown in Fig. 6. The proposed consumer demands analysis in the eWOM procedure consists mainly of eWOM collection, appraisal extraction, appraisal word classification and consumer demands identification, as described in the sections that follow.

eWOM collection eWOM content is collected from the Internet with content collection and identification technologies, as follows:
- Content collection: The names of products, services, and companies are the keywords that are searched for in the web content.

- eWOMidentification: The collected web content is filtered for appraisal words.

Appraisal extraction Semantic analysis and content extraction are conducted using the eWOM content to identify appraisal words related to the target products or services:

- Parts of speech tagging: All of the parts of speech in the text are identified.

- Appraisal analysis: Sentiment analysis technologies monitor unknown appraisal words.

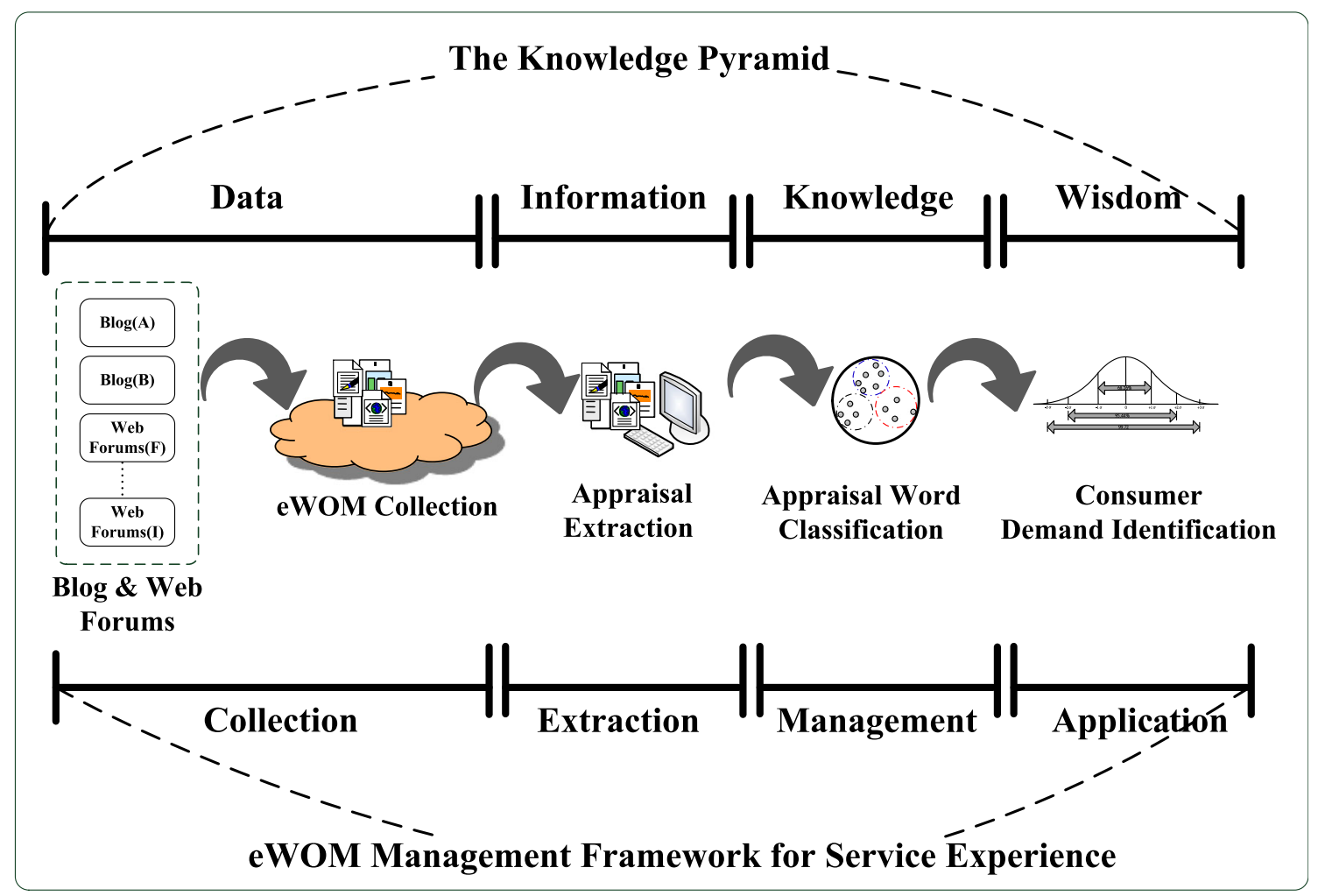

Fig. 5 Consumer demands analysis model in eWOM 


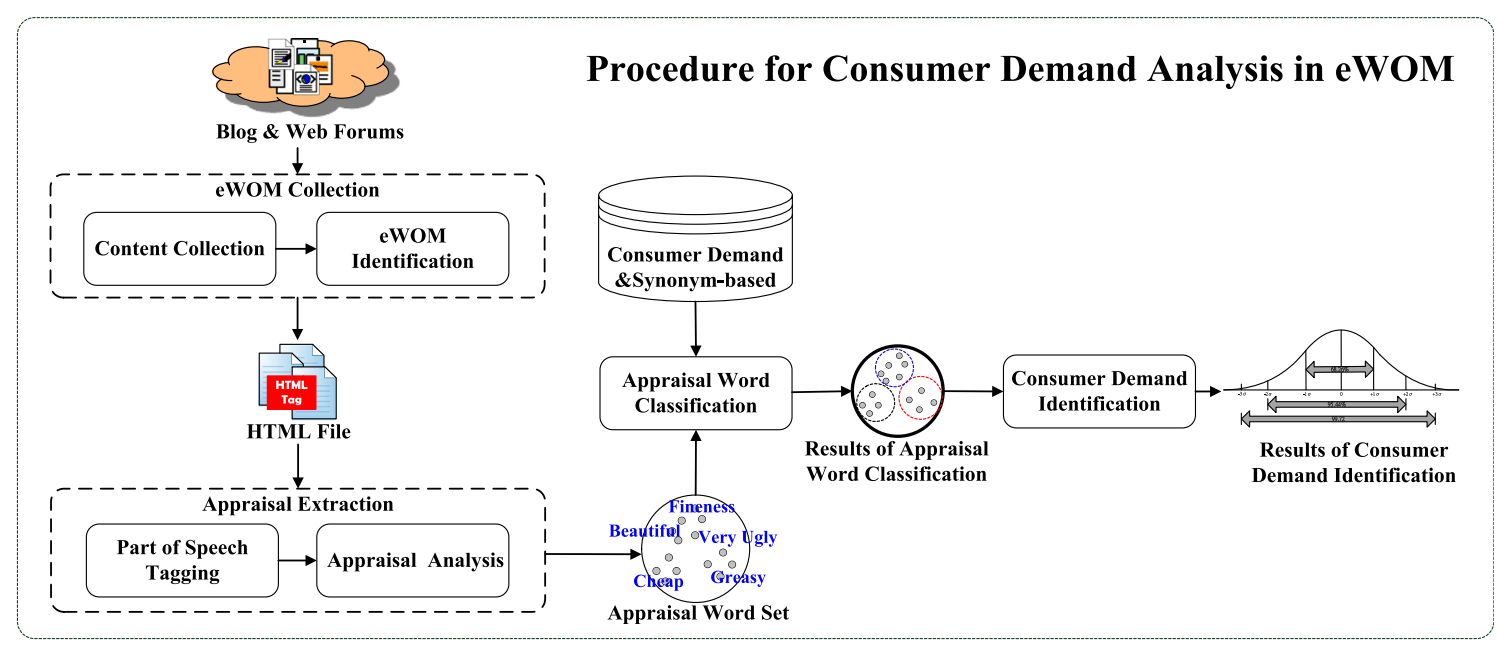

Fig. 6 The procedure for consumer demand analysis from eWOM

Appraisal word classification Appraisal words include consumer demands. Therefore, this study uses calculations of similarity to determine the relationships between appraisal words and consumer demands. The classifications for appraisal words are then used to calculate the frequencies of the appearance of appraisal words in consumer demand factors. The number of appearances are saved month-by-month.

Consumer demand identification By analyzing the frequencies of appraisal words in relation to consumer demand factors, consumer demand identification is conducted to identify changes in these demands.

\section{eWOM collection}

In order to effectively collect eWOM content, a collection method was developed to extract specific content related to eWOM communication and to exclude non-related content (Fig. 7). The eWOM collection processes mainly include "content collection" and "eWOM identification", as described below:

Content collection To ensure efficient and accurate collection of related content (about specific products, services, or brands), the following processes and technologies were developed.

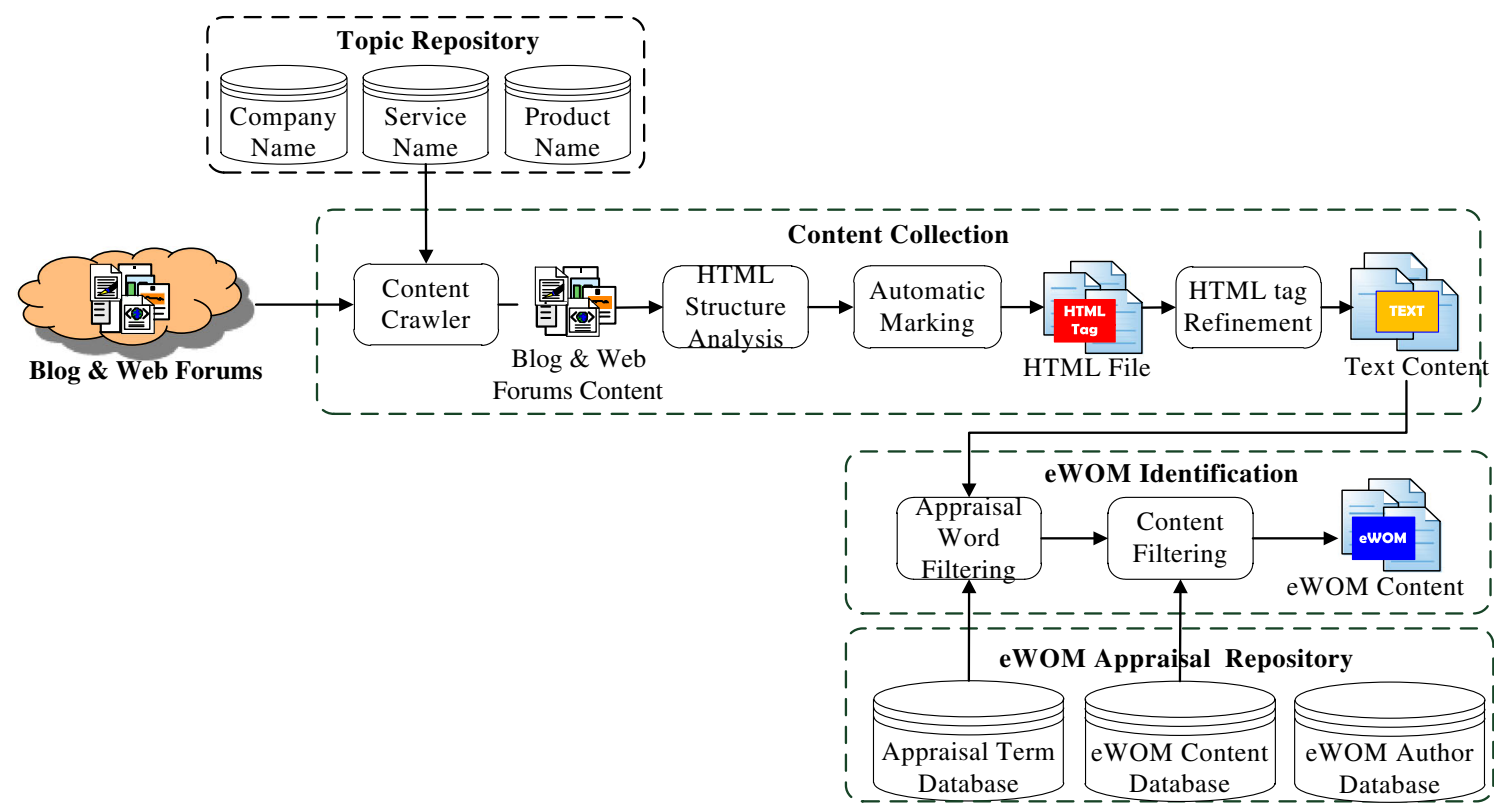

Fig. 7 eWOM collection process 


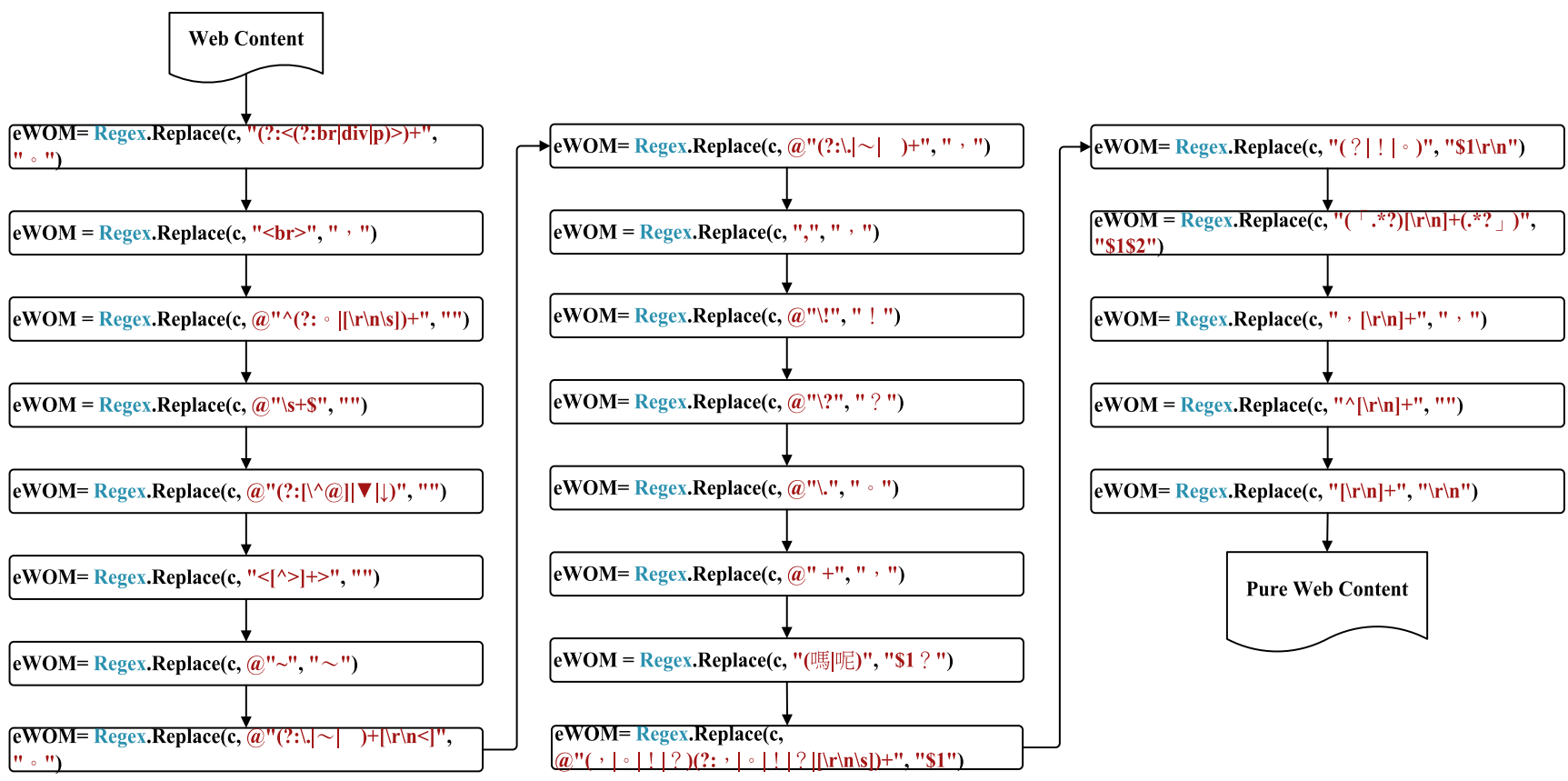

Fig. 8 Automatic punctuation rules

- Content crawler: By searching web content using keywords (e.g., products, services, or brands), items of interest are extracted from blogs and online communities via the Google API (Application Programming Interface).

- HTML structure analysis: Each blog and online community has a unique HTML tag format. After obtaining the web content, the HTML structure is analyzed to facilitate extraction.

- Automatic marking: Web content is often presented in semi- or non-structured formats. Analyses of web content is generally hampered by the use of "text speak", special symbols for certain online communities, a lack of punctuation, and other challenging characteristics. To address these problems, an automatic marking function is developed to analyze and categorize HTML language. This also punctuates the eWOM content with the aid of a rule database, thus improving the accuracy of the analysis of the parts of speech in Chinese texts (Fig. 8).

- HTML tag refinement: Tag refinement is primarily applied to eliminate advertisements and HTML language links, and thus only the important parts of the web content are retained, improving the efficiency of the follow-up procedures. This content is saved as a "*.txt" file.

eWOM identification The collected web content might still include information not related to eWOM communications.
The following filters are applied to extract only the required content.

- Appraisal word filtering: An appraisal word database is employed to locate web content that includes the appraisal words.

- Content filtering: Repeated content is deleted from the selected web content.

\section{Appraisal extraction}

Despite applying the above-mentioned filtering processes, the content still included some unidentified appraisal words. The following techniques were applied to determine the appraisal words that are commonly used by consumers, as shown in Fig. 9.

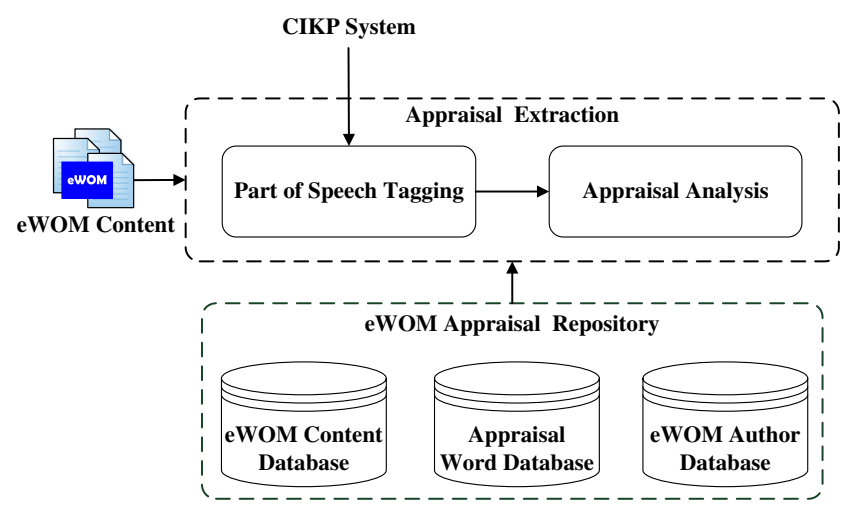

Fig. 9 Appraisal extraction process 
Parts of speech tagging The Chinese Knowledge Information Processing (CKIP) system, developed by Academia Sinica in Taiwan, is used to tag parts of speech.

Appraisal analysis Consumer opinions have been frequently analyzed with sentiment analysis technologies (He and Zhou 2011; Fan and Chang 2010; Vechtomova 2010), and a variety of methods can be used with Chinese text. For instance, Pai et al. employed the Chinese sentiment analysis method proposed by $\mathrm{Ku}$ et al. (2005) to develop an eWOM analytical method (Pai et al. 2013a), further developing a SWOT analytical technique (Pai et al. 2013b) using the results of eWOM analysis. This work thus uses the analytical method in Pai et al. (2013a) and $\mathrm{Ku}$ et al. (2005) as the basis of appraisal analysis, with the following steps applied for analysis of unknown appraisal words.

First and foremost, this study conducted a calculation of the appraisal character weight, which indicates positive or negative values, as calculated with eqs. (1) and (2).

$P_{c i}=\frac{f p_{c i}}{f p_{c i}+f n_{c i}}$

$N_{c i}=\frac{f n_{c i}}{f p_{c i}+f n_{c i}}$

where $c i$ is the $i^{\text {th }}$ character in the appraisal character set, $f p_{c i}$ is the number of times appraisal character $c i$ appears in the positive appraisal word database; $f n_{c i}$ is the number of times appraisal character $c i$ appears in the negative appraisal word database; $P_{c i}$ is the positive weight of the appraisal character $c i$, and $N_{c i}$ is the negative weight of the appraisal character $c i$.

Equations (1) and (2) denote the number of times an appraisal character appears in the positive and negative appraisal word databases. Equations (3) and (4) regularize eqs. (1) and (2), respectively.

$N P_{c i}=\frac{f p_{c i} / \sum_{j=1}^{n} f p_{c j}}{f p_{c i} / \sum_{j=1}^{n} f p_{c j}+f p_{c i} / \sum_{j=1}^{m} f n_{c j}}$

$N N_{c i}=1-N P_{c i}$

where $f p_{c i}$ is the number of times appraisal character $c i$ appears in the positive appraisal word database; $f n_{c i}$ is the number of times appraisal character $c i$ appears in the negative appraisal word database; $n$ is the total number of appraisal words in the positive appraisal word database, and $m$ is the total number of appraisal words in the negative appraisal word database; $N P_{c i}$ is the positive weight of appraisal character $c i$ in the positive appraisal word database, and $N N_{c i}$ is the negative weight of appraisal character $c i$ in the negative appraisal word database. The above-mentioned formulae are applied to weigh the appraisal characters, with the results shown in Table 2.

Based on these results, we carried out a calculation of appraisal word weight. In $e q$. (5), $S_{c j}$ is the appraisal character weight of each appraisal character. $N P_{c i}$ and $N N_{c i}$ are the positive and negative weights of the appraisal characters, respectively, and are used to assess the meanings of these characters. For example, if $N P_{c i}$ is greater than $N N_{c i}$, the appraisal character is positive, and vice versa.

$S_{c i}=N P_{c i}-N N_{c i}$

$S_{w}=\frac{1}{p} \times \sum_{j=1}^{p} S_{c j}$

Equation (6) primarily evaluates whether the appraisal word is positive or negative. $S_{w}$ is the weight of the appraisal word, and is either positive or negative, $p$ is the number of appraisal characters in the appraisal word, and $S_{c j}$ is the appraisal character weight of each appraisal character. Table 3 gives the results of this process.

\section{Appraisal word classification}

Based on the analysis of the relationships between appraisal words and consumer demands carried out above, processes were designed to analyze the relationships between appraisal words and consumer demand factors by calculating the frequencies with which the appraisal words were found in consumer demand occurrences. This study analyzed the words with similar meanings in both appraisal words and consumer demand factors, with the results used as the basis for the categorization of the former. This study found the following $21 \mathrm{de}-$ mand factors in a review of the literature: reliability, responsiveness, competence, access, courtesy, communication, credibility,

Table 2 Results of analyzing appraisal character weights

\begin{tabular}{lll}
\hline Appraisal character & $\begin{array}{l}\text { Positive weight } \\
\left(N P_{c i}\right)\end{array}$ & $\begin{array}{l}\text { Negative weight } \\
\left(N N_{c i}\right)\end{array}$ \\
\hline 安 (quiet or calm) & $0.941,599,576$ & 0.0512821 \\
靜 (still or quiet) & $0.905,542,268$ & 0.0833333 \\
藹 (friendly or gentle) & $0.874,563,777$ & $0.11,111,111$ \\
然 (but or just like that) & $0.616,398,111$ & $0.3,516,483$ \\
可 (approve) & $0.558,651,364$ & $0.4,077,669$ \\
親 (parents) & $0.753,106,429$ & $0.2,222,222$ \\
好 (good) & $0.759,573,109$ & $0.2,162,162$ \\
康 (healthy or abundant) & $0.796,824,389$ & $0.1,818,182$ \\
\hline
\end{tabular}


Table 3 Results of analyzing appraisal word weight

\begin{tabular}{lll}
\hline Appraisal word & Appraisal character weight $\left(S_{c i}\right)$ & Appraisal word weight $\left(S_{w}\right)$ \\
\hline 安靜 (peaceful) & $\begin{array}{l}\text { 安 (quiet or calm) }=0.890,317,525 \\
\text { 靜 }(\text { still or quiet })=0.822,208,935 \\
\text { 好康 }(\text { good deal) }\end{array}$ & $\begin{array}{l}\text { 好 (good) }=0.543,356,893 \\
\text { 康 (healthy or abundant) }=0.615,006,207\end{array}$ \\
\hline
\end{tabular}

security, understanding/knowing, tangibles, food quality, food price, food innovation, food rarity, natural food, food flavor, food mouthfeel, serving size, convenience of location, restaurant environment and restaurant style (Currie et al. 2009; Liu and Jang 2009; Ziethmal and Bitner 2003; French et al. 2000; Kivela et al. 1999; Earle 1997; Lee and Ulgado 1997). This study then constructed a database containing synonyms for all of these demand factors. There were two sources for this database. The first was the manual collection and classification of synonyms. The second was a comparison between the results of appraisal word classification and the synonyms database. Through this process, the synonyms that were not in the database were collected.

The Jaccard coefficient was applied to calculate the similarity between appraisal words and the synonym corpus for the consumer demand factors. Their similarity was analyzed, and the results used as the basis for categorizing the appraisal words, using eq. (7).

$\operatorname{sim}\left(a_{k}, d_{i j}\right)=\left|\frac{a_{k} \cap d_{i j}}{a_{k} \cup d_{i j}}\right|$

Based on eq. (7), the results of appraisal word classification are listed in Table $4 . a_{k}$ is the appraisal word set, $a_{k} \in\left\{a_{1}, a_{2}, a_{3}, \ldots, a_{E}\right\}$, and $E$ indicates the number of appraisal word $\operatorname{sets}(k=1 \sim Z)$. As for " $d_{i j}$ ", $i$ is the number of consumer demand factors, $j$ is the ranking of the synonym in the corpus. This study uses appraisal word sets and the synonym corpus of consumer demand factors to construct a binary matrix, as shown in eq. (8).

$\operatorname{sim}\left(a_{k}, d_{i j}\right)=\left[\begin{array}{cccc}\operatorname{Max}\left[\operatorname{sim}\left(a_{1}, d_{1 j}\right)\right] & \operatorname{Max}\left[\operatorname{sim}\left(a_{1}, d_{2 j}\right)\right], & \cdots, & \operatorname{Max}\left[\operatorname{sim}\left(a_{1}, d_{j}\right)\right] \\ \operatorname{Max}\left[\operatorname{sim}\left(a_{2}, d_{1 j}\right)\right], & \operatorname{Max}\left[\operatorname{sim}\left(a_{2}, d_{2 j}\right)\right], & \cdots, & \operatorname{Max}\left[\operatorname{sim}\left(d_{2}, d_{i j}\right)\right] \\ \ldots \ldots & \ldots \ldots & \ldots \ldots \\ \operatorname{Max}\left[\operatorname{sim}\left(a_{k}, d_{1 j}\right)\right], & \operatorname{Max}\left[\operatorname{sim}\left(a_{k}, d_{2 j}\right)\right], & \cdots, & \operatorname{Max}\left[\operatorname{sim}\left(a_{k}, d_{i j}\right)\right]\end{array}\right]$

In the binary matrix, $\operatorname{sim}\left(a_{k}, d_{i j}\right)$ indicates the similarity between the appraisal word set and consumer demand factors. If the value of similarity between appraisal words and consumer demand factors is high, then the value of $\operatorname{sim}\left(a_{k}, d_{i j}\right)$ will almost be equal to 1 , while the value of $r\left(a_{m}, b_{n}\right)$ will be near or equal to 0 , as can be seen in Table 4 .

Table 4 The similarity between the appraisal word set and consumer demand factors

\begin{tabular}{llllllllllllll}
\hline $\mathrm{CDF}$ & $d_{l j}$ & $d_{2 j}$ & \multicolumn{1}{c}{$d_{3 j}$} & $d_{4 j}$ & $d_{5 j}$ & $d_{6 j}$ & $d_{7 j}$ & $d_{8 j}$ & $\ldots$ & $d_{18 j}$ & $d_{19 j}$ & $d_{20 j}$ & $d_{2 l j}$ \\
$\mathrm{AW}$ & & & & & & & & & & & & \\
\hline$a_{1}$ & 0.000 & 0.943 & 0.000 & 0.000 & 0.000 & 0.218 & 0.142 & 0.333 & $\ldots$ & 0.142 & 0.000 & 0.000 & 0.000 \\
$a_{2}$ & 0.000 & 0.139 & 1 & 0.189 & 0427 & 0.000 & 0.000 & 0.000 & $\ldots$ & 0.086 & 0.478 & 0.776 & 0.000 \\
$a_{3}$ & 1 & 0.000 & 0.000 & 0.000 & 0.000 & 0.219 & 0.000 & 0.142 & $\ldots$ & 0.147 & 0.499 & 0.200 & 0.000 \\
$a_{4}$ & 0.000 & 0.652 & 1 & 0.000 & 0.053 & 0.000 & 0.208 & 0.189 & $\ldots$ & 0.000 & 0.037 & 0.707 & 0.000 \\
$a_{5}$ & 0.152 & 0.153 & 0.000 & 0.635 & 1 & 0.196 & 0.000 & 0.000 & $\ldots$ & 0.000 & 0.000 & 0.000 & 0.000 \\
$a_{6}$ & 0 & 1 & 0 & 0 & 0 & 0.0 & 0 & 0 & $\ldots$ & 0.153 & 0 & 0 \\
$a_{7}$ & 0.000 & 0.000 & 0.460 & 0.189 & 0.905 & 0.443 & 0.000 & 1 & $\ldots$ & 0.362 & 0.000 & 0.111 & 0.142 \\
$a_{8}$ & 0.000 & 0.000 & 0.783 & 0.382 & 0.000 & 0.381 & 0.000 & 0.154 & $\ldots$ & 0.000 & 0.383 & 1 \\
$a_{9}$ & 0.000 & 0.000 & 0.000 & 0.000 & 0.000 & 0.000 & 0.000 & 0.000 & $\ldots$ & 1 & 0.000 & 0.000 & 0.0000 \\
$a_{10}$ & 0.000 & 0.359 & 0.000 & 1 & 0.000 & 0.000 & 0.000 & 0.000 & $\ldots$ & 0.390 & 0.183 & 0.000 & 0.000 \\
\hline
\end{tabular}

CDF: consumer demand factors; AW: appraisal word set. 
In order to program the categorization of appraisal words, this study uses eq. 8 to design the algorithm for appraisal word classification, as shown in Table 5.
The frequencies at which consumer demands occur are saved through the method of appraisal word classification. As shown in Table $6, t_{n}$ indicates the number in each month,

Table 5 Algorithm of appraisal word classification

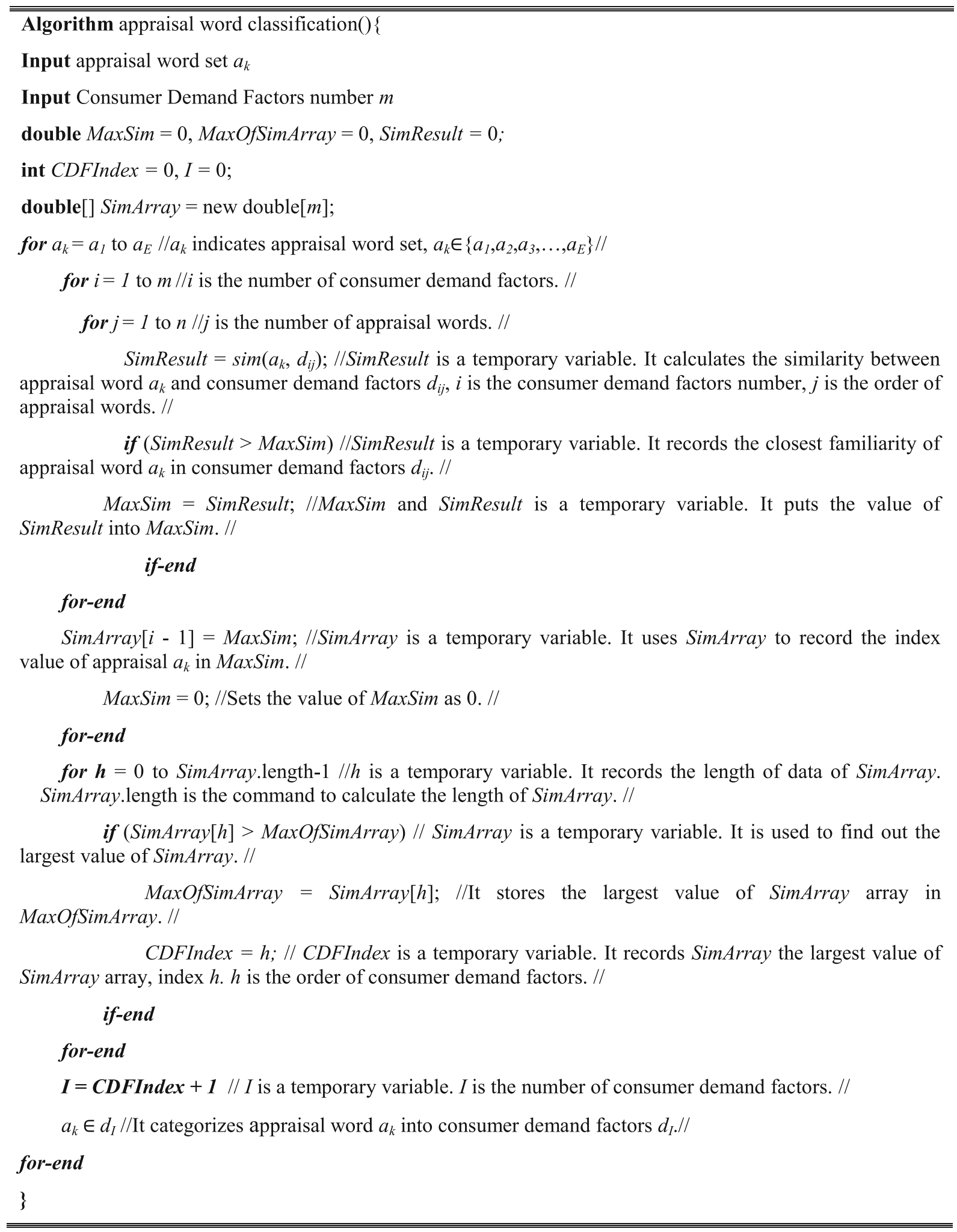




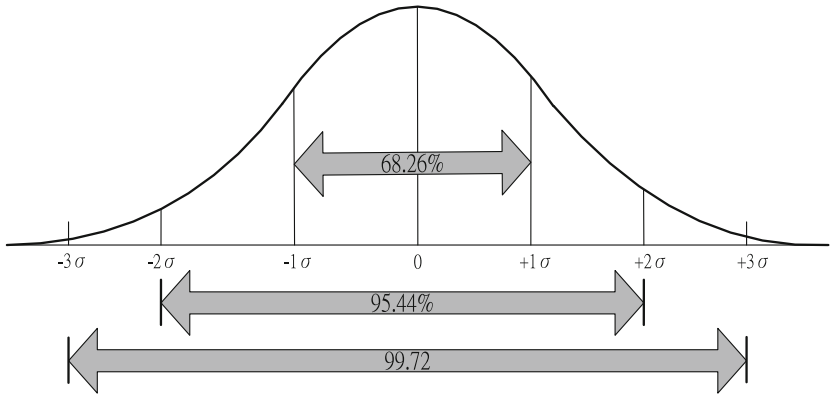

Fig. 10 Estimation and confidence intervals

and $\left(t \in\left\{t_{n}, t=1,2,3, \ldots, n\right\}\right), D F_{1}$ to $D F_{21}$ stand for consumer demand factors, including reliability, responsiveness, competence, access, courtesy, communication, credibility, security, understanding/ knowing, tangibles, food quality, food price, food innovation, food rarity, natural food, food flavor, food mouth feel, serving size, convenience of location, restaurant environment and restaurant style, respectively.

\section{Consumer demands identification}

Based on the results of appraisal word classification, the frequency with which appraisal words are found in consumer demand factors each month could be calculated. To translate

Table 6 The frequency of consumer demand occurrence

\begin{tabular}{lllllllllll}
\hline & $t_{1}$ & $t_{2}$ & $t_{3}$ & $t_{4}$ & $t_{5}$ & $t_{6}$ & $\ldots$ & $\ldots$ & $\ldots$ & $t_{n}$ \\
\hline$D F_{1}$ & 870 & 414 & 960 & 626 & 80 & 406 & $\ldots$ & $\ldots$ & $\ldots$ & 679 \\
$D F_{2}$ & 954 & 12 & 339 & 828 & 989 & 45 & $\ldots$ & $\ldots$ & $\ldots$ & 293 \\
$D F_{3}$ & 324 & 592 & 14 & 362 & 409 & 411 & $\ldots$ & $\ldots$ & $\ldots$ & 329 \\
$D F_{4}$ & 745 & 780 & 564 & 874 & 559 & 19 & $\ldots$ & $\ldots$ & $\ldots$ & 911 \\
$D F_{5}$ & 144 & 683 & 49 & 507 & 349 & 601 & $\ldots$ & $\ldots$ & $\ldots$ & 338 \\
$D F_{6}$ & 416 & 241 & 734 & 62 & 653 & 773 & $\ldots$ & $\ldots$ & $\ldots$ & 256 \\
$D F_{7}$ & 510 & 148 & 46 & 531 & 782 & 426 & $\ldots$ & $\ldots$ & $\ldots$ & 377 \\
$D F_{8}$ & 654 & 992 & 785 & 448 & 764 & 212 & $\ldots$ & $\ldots$ & $\ldots$ & 614 \\
$D F_{9}$ & 161 & 815 & 681 & 93 & 116 & 550 & $\ldots$ & $\ldots$ & $\ldots$ & 804 \\
$D F_{10}$ & 377 & 676 & 806 & 894 & 893 & 278 & $\ldots$ & $\ldots$ & $\ldots$ & 938 \\
$D F_{11}$ & 878 & 713 & 449 & 373 & 522 & 598 & $\ldots$ & $\ldots$ & $\ldots$ & 913 \\
$D F_{12}$ & 677 & 302 & 169 & 142 & 155 & 590 & $\ldots$ & $\ldots$ & $\ldots$ & 718 \\
$D F_{13}$ & 79 & 808 & 416 & 465 & 444 & 168 & $\ldots$ & $\ldots$ & $\ldots$ & 343 \\
$D F_{14}$ & 544 & 648 & 194 & 895 & 720 & 29 & $\ldots$ & $\ldots$ & $\ldots$ & 992 \\
$D F_{15}$ & 952 & 50 & 814 & 144 & 799 & 493 & $\ldots$ & $\ldots$ & $\ldots$ & 666 \\
$D F_{16}$ & 201 & 467 & 173 & 809 & 740 & 854 & $\ldots$ & $\ldots$ & $\ldots$ & 115 \\
$D F_{17}$ & 109 & 202 & 998 & 226 & 764 & 730 & $\ldots$ & $\ldots$ & $\ldots$ & 184 \\
$D F_{18}$ & 4 & 61 & 287 & 747 & 416 & 802 & $\ldots$ & $\ldots$ & $\ldots$ & 815 \\
$D F_{19}$ & 991 & 60 & 817 & 37 & 582 & 230 & $\ldots$ & $\ldots$ & $\ldots$ & 912 \\
$D F_{20}$ & 504 & 476 & 709 & 282 & 19 & 845 & $\ldots$ & $\ldots$ & $\ldots$ & 131 \\
$D F_{21}$ & 944 & 474 & 4 & 186 & 893 & 167 & $\ldots$ & $\ldots$ & $\ldots$ & 784 \\
\hline & & & & & & & & & &
\end{tabular}

these numbers into tangible enterprise knowledge, this research designs a consumer demands identification technique which analyzes and identifies changes in consumer demands. This technique is explained below.

As shown in Fig. 10, consumer demand in each factor includes many appraisal words. According to the central limit theorem, when the sampling number of appraisal words is $n \geq 30$, the consumer demands in each factor are normally distributed. Therefore, this research assumes that the consumer demands in each factor are normally distributed, and under the $95 \%$ confidence interval the frequencies of consumer demand occurrences would fall into the range of $[\mu+2 \sigma, \mu-2 \sigma]$. Therefore, when the frequency of consumer demands found in consumer demand occurrences is out of the $95 \%$ confidence interval range, then this is defined as an obvious change in consumer demand factors.

Equation (9) calculates the mean value of the frequency of consumer demand occurrences per month, where $t$ is the time set $\left(t \in\left\{t_{j}, t=1,2,3, \ldots, n-1\right\}\right)$. Equation (10) calculates the standard deviation for the frequency of consumer demand occurrences, where $x_{t}$ stands for the frequency of consumer demand occurrences for each month.

$\mu=\frac{1}{n-1} \sum_{t=1}^{n-1} x_{t}$

$\sigma=\sqrt{\frac{1}{n-2} \sum_{t=1}^{n-1}\left(x_{t}-\mu\right)^{2}}$

Using the example, we explain the results of the calculations from eqs. (9) and (10). As summarized in Table 7, $t_{n}$ specifies the time set, $\mu$ stands for the mean value, $\sigma$ stands for the standard deviation, and DC indicates whether consumer demands have changed. If the company is interested in whether consumer demand factors have changed in $t_{10}$, we should first use Table 7 to find out the frequencies of appearance for $D F_{1} \sim D F_{21}$ during $t_{10}$, and if the frequencies of the appearance of consumer demand factors $\left(D F_{1} \sim D F_{21}\right)$ are larger than $\mu+2 \sigma$ or smaller than $\mu-2 \sigma$ during $t_{10}$, this indicates the consumer demands factors have changed. On the other hand, if the frequencies of the appearance of consumer demand factors $\left(D F_{1} \sim D F_{21}\right)$ are smaller than $\mu+2 \sigma$ or larger than $\mu-2 \sigma$ during this time, this indicates that consumer demand factors have not changed.

\section{Case study}

Based on the above-mentioned analysis tools, this study develops a computer-based approach for analyzing consumer demands. This section describes an implementation of this system using $\mathrm{C \#}$, and a case study is used to evaluate the effectiveness of this approach. 
Fig. 11 Collection of eWOM content

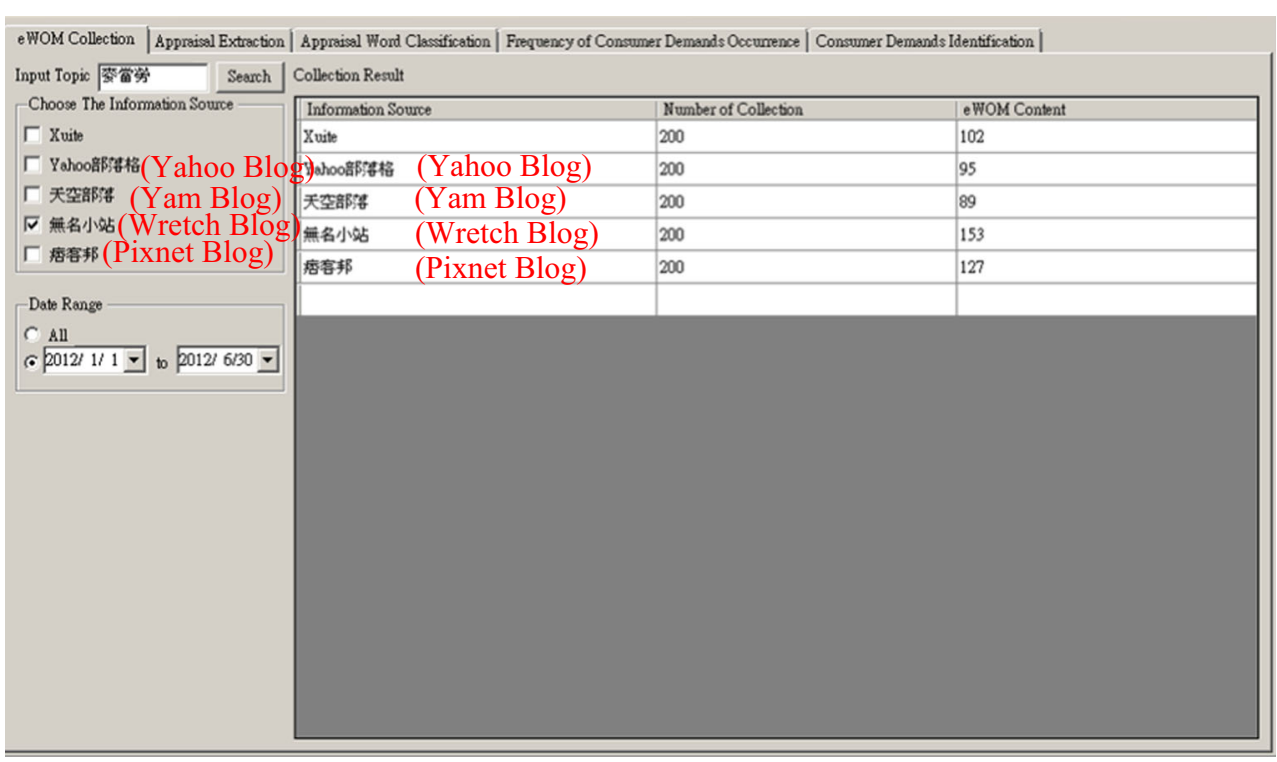

\section{Prototype}

The research set-up includes an Intel Core2 Duo E64202.13G PC, running Microsoft Windows XP Professional, Internet Information Services (IIS), Microsoft SQL Server 2008, and Microsoft Visual Studio 2010.

Screenshots of the system are presented in Figs. 11-15. Fig 11 shows the user interface screen for content collection, Fig. 12 shows the semantic analysis and extraction of the content, while Fig. 13 shows the classification of the appraisal words. Fig. 14 shows the frequency results of consumer demand occurrence, and Fig. 15 presents the results of consumer demands identification.

\section{System evaluation from a user satisfaction perspective}

In order to examine the effectiveness of the proposed mechanism and assist strategic planning managers, marketing personnel, and R\&D personnel to carry out marketing strategies, this study used a user satisfaction questionnaire to conduct a system evaluation, adopting the approach from Li and Chang (2009), Chen and Chen (2012), and Pai et al. (2013b). The
Fig. 12 Semantic analysis and extraction of eWOM content

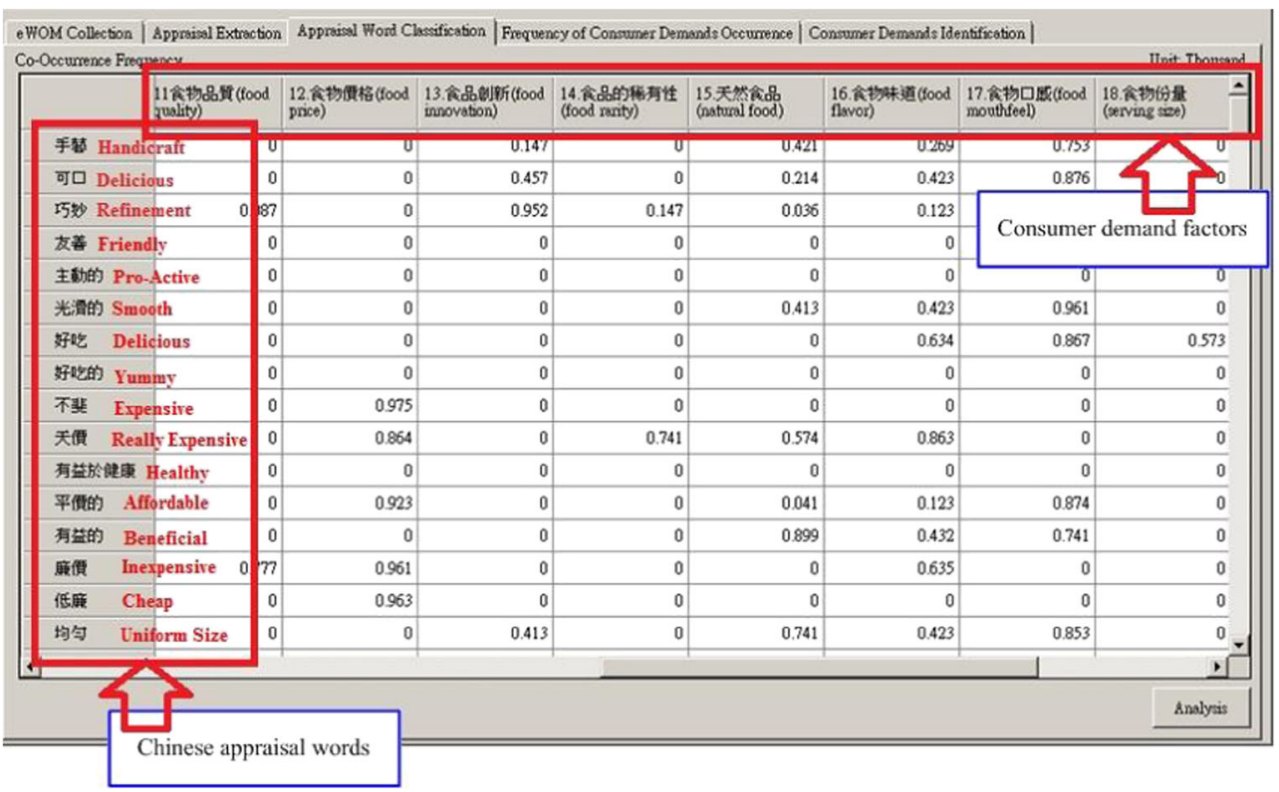


Fig. 13 Classification of appraisal words

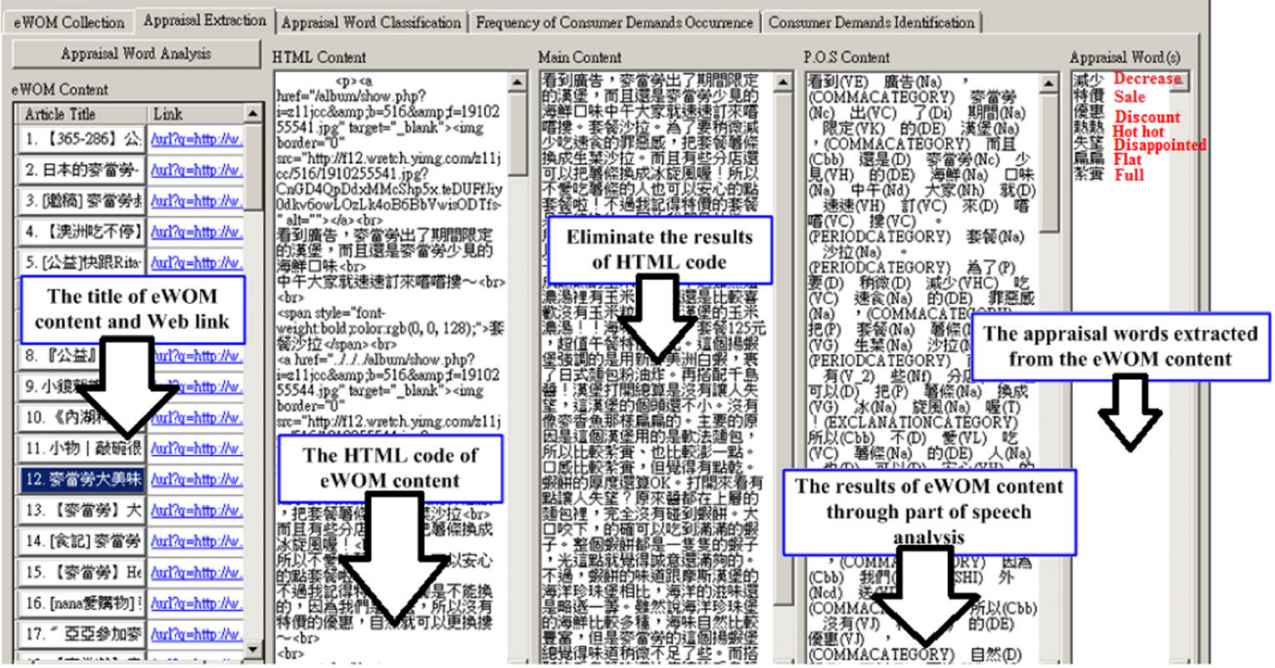

literature review was used as the basis of this study, and the results were used to carry out the design of user satisfaction questionnaires items. The items in the instrument were rated on a five-point Likert scale, with $1=$ strongly disagree, $3=$ undecided, and $5=$ strongly agree.

This research was conducted using both control and experimental groups. The results of a system evaluation showed that the proposed method could be used as an effective basis for product and service planning, and that it could assist strategic planning managers, marketing personnel, as well as research and development departments. In the case of the control group, the participants evaluated the traditional questionnaire surveys on consumer needs. For the experimental group, the participants were provided access to the proposed method and were then surveyed on their opinions as to the accuracy and effectiveness of the method, given their professional knowledge and judgment. Finally, based on the surveys of the two groups and a t-test, we analyzed the level of satisfaction with these methods to determine whether any significant differences existed between the traditional approaches (marketing surveys) for analyzing consumer demands and the proposed approach. Convenience sampling was applied in this study, and the questionnaires were administered to students of executive master of business administration (EMBA) programs from three universities in southern Taiwan. The students were asked to evaluate the system used in this study. However, only one of the universities was willing to fully participate
Fig. 14 Frequency results of consumer demands occurrence

\begin{tabular}{|c|c|c|c|c|c|c|c|c|c|c|c|c|c|}
\hline \multirow{2}{*}{\multicolumn{2}{|c|}{$\begin{array}{l}\text {-WOM Collection | Appraisal Extraction | Appraisal Wond Clasification } \\
\text { Calculate Frequency of Appraisal Wond in Consumer Demands }\end{array}$}} & \multicolumn{5}{|c|}{ Frequency of Consuner Demasds Occumence |c } & \multicolumn{7}{|c|}{ Consumer Demands Identification | } \\
\hline & & & & & & & & & & & & & \\
\hline \multicolumn{14}{|c|}{ Time of Occunence Year $2012 \sim$ Month: $6 \nabla$ Enter } \\
\hline 106 & 201107 & 201108 & 201109 & $2011 / 10$ & $2011 / 11$ & $2011 / 12$ & 201201 & 201202 & 201203 & 201204 & 201205 & 201206 & $\triangle$ \\
\hline 01. 叮察性(Relinbility) & 718 & 311 & 1702 & 1282 & 1008 & 0 & 1608 & 1302 & 224 & 483 & 1106 & 1336 & \\
\hline 02. 国應性(respontivenesu) & 909 & 1140 & 1181 & 966 & 902 & 337 & 1875 & 251 & 1677 & 1453 & 598 & 1875 & \\
\hline 03脂任性(competrnce) & 1313 & 1225 & 1897 & 1311 & 20 & 1342 & 375 & 1366 & 1263 & 496 & 1413 & 1243 & \\
\hline 04 辎近(access) & 1169 & 1806 & 1201 & $m$ & 80 & 1267 & 575 & 608 & 812 & 1313 & 459 & 1256 & \\
\hline 05. & 1787 & 390 & 1757 & 280 & 1925 & 714 & 174 & 213 & 1461 & 1794 & 55 & 1690 & \\
\hline 06浶通 (communacation) & 236 & 250 & 557 & 1065 & 88 & 498 & 1241 & 1319 & 849 & 1902 & 19 & 1638 & \\
\hline 07.信櫝(credibility) & 1145 & 1811 & 293 & 768 & 1864 & 374 & 835 & 912 & 1876 & 1222 & 24 & 1879 & \\
\hline 08安全(secunty) & 1870 & 1342 & 67 & 1210 & 1515 & 1597 & 995 & 742 & 1321 & 460 & 1260 & 1909 & \\
\hline 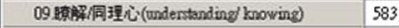 & 1824 & 1041 & 945 & 1839 & 404 & 509 & 1006 & 1096 & 1143 & 55 & 832 & 867 & \\
\hline 10.有形(tangibles) & 1182 & 480 & 386 & 1527 & 104 & 1046 & 859 & 291 & 763 & 1082 & 963 & 807 & \\
\hline 11会彷品筫 (food quality) & 1119 & 522 & 1815 & 1391 & 468 & 1199 & 233 & 776 & 532 & 1699 & 1330 & 1430 & \\
\hline 12. 食物偵格(food price) & 1917 & 136 & 1036 & 908 & 35 & 1777 & 49 & 1222 & 1748 & 1146 & 599 & 1271 & \\
\hline 13.食品斯(food innovation) & 547 & 647 & 984 & 1016 & 511 & 1754 & 1874 & 1210 & 1659 & 271 & 283 & 642 & \\
\hline 14.食品的粚有性(food rarity) & 1203 & 836 & 1638 & 1632 & 865 & 550 & 1555 & 1139 & 125 & 1008 & 1183 & 1350 & \\
\hline 15 天然食品(natural food) & 1825 & 1245 & 148 & 875 & 302 & 1339 & 811 & 553 & 112 & 1295 & 1874 & 62 & \\
\hline 16.会物珠道(food flavor) & 1173 & 1943 & 1703 & 1094 & 83 & 261 & 148 & 727 & 305 & 685 & 1102 & 158 & \\
\hline 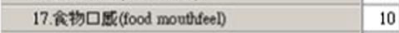 & 913 & 67 & 536 & 1765 & 215 & 951 & 138 & 267 & 1059 & 1420 & 181 & 428 & \\
\hline 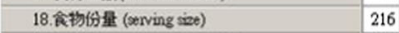 & 962 & 177 & 883 & 491 & 808 & 1260 & 58 & 516 & 245 & 1809 & 1188 & 1677 & \\
\hline 19.位置(convenience of bcation) & 1616 & 563 & 890 & 20 & 1684 & 1379 & 960 & 1078 & 17 & 1773 & 199 & 1372 & \\
\hline \multirow[t]{2}{*}{ 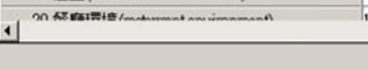 } & $\ln 2 n$ & 764 & $x$ & IAx & $57 x$ & 1076 & $11 \mathrm{Ka}$ & oøo & $\sin$ & $1 \mathrm{kn}$ & 1674 & 1206 & \\
\hline & & & & & & & & & & & & Next & \\
\hline
\end{tabular}


Fig. 15 Results of consumer demands identification

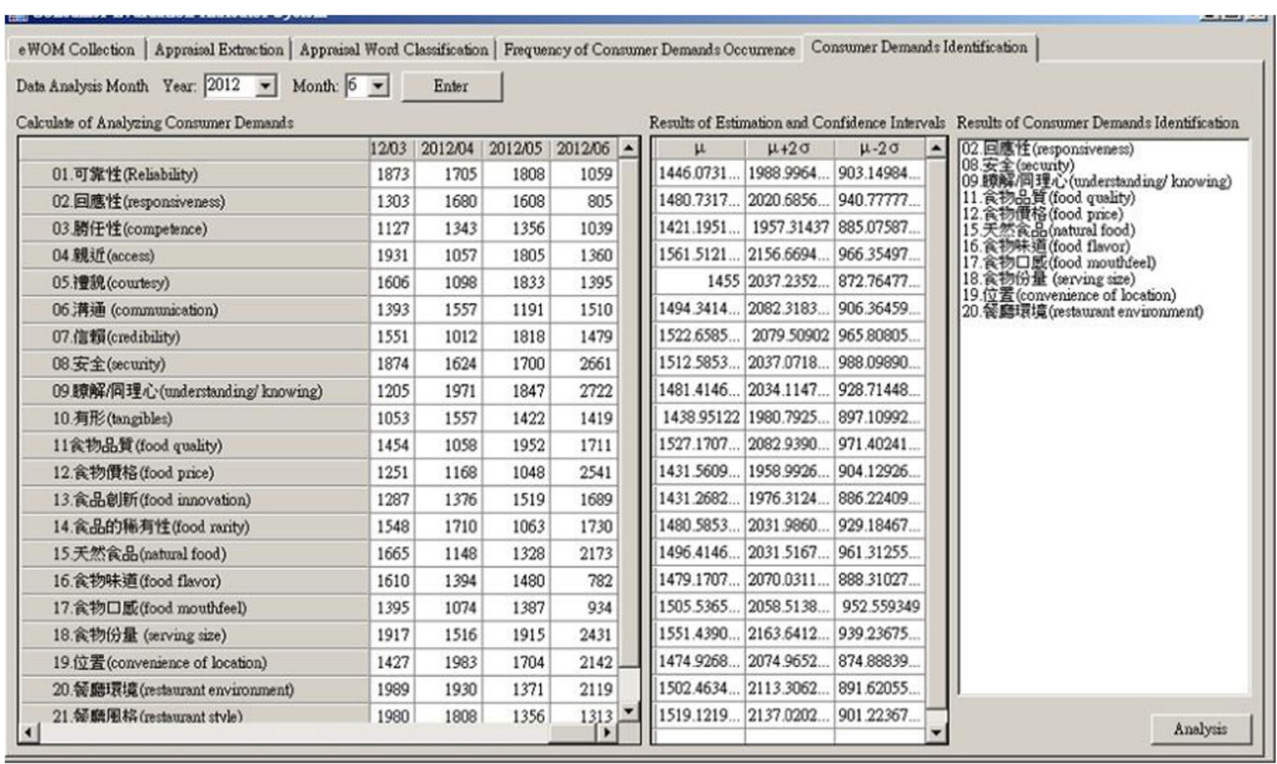

in this work, and only eighteen participants were willing to take part in the evaluation of the system. These participants who took part in the experiment all had a bachelor's degree in business administration, and were mainly from small and medium-sized enterprises in Taiwan. The participants included strategic planning managers and marketing personnel, as well as research and development personnel. Each participant had to possess related knowledge and real-world experience of using marketing surveys and consumer demand analysis. When the participants took part in

Table 7 Consumer demands identification

\begin{tabular}{|c|c|c|c|c|c|c|c|c|c|c|c|c|c|c|c|}
\hline & \multicolumn{11}{|c|}{ Time set $t(t=1 \sim n)$} & \multirow[b]{2}{*}{$\mu$} & \multirow[b]{2}{*}{$\mu+2 \sigma$} & \multirow[b]{2}{*}{$\mu-2 \sigma$} & \multirow[b]{2}{*}{ DC } \\
\hline & & $t_{1}$ & $t_{2}$ & $t_{3}$ & $t_{4}$ & $t_{5}$ & $t_{6}$ & $t_{7}$ & $t_{8}$ & $t_{9}$ & $t_{10}$ & & & & \\
\hline \multirow[t]{21}{*}{ Consumer demand factors $j(j=1 \sim 21)$} & $D F_{1}$ & 92 & 66 & 86 & 51 & 54 & 91 & 59 & 93 & 22 & 49 & 68 & 114 & 70 & $\mathrm{Y}$ \\
\hline & $D F_{2}$ & 43 & 15 & 30 & 17 & 41 & 73 & 47 & 26 & 53 & 54 & 38 & 73 & 37 & \\
\hline & $D F_{3}$ & 34 & 38 & 76 & 45 & 3 & 16 & 94 & 21 & 8 & 91 & 37 & 95 & 28 & \\
\hline & $D F_{4}$ & 29 & 83 & 90 & 29 & 73 & 92 & 19 & 25 & 76 & 82 & 57 & 116 & 59 & \\
\hline & $D F_{5}$ & 75 & 83 & 100 & 69 & 36 & 43 & 20 & 45 & 96 & 19 & 63 & 116 & 57 & $\mathrm{Y}$ \\
\hline & $D F_{6}$ & 32 & 32 & 61 & 8 & 95 & 74 & 3 & 5 & 45 & 99 & 39 & 101 & 29 & \\
\hline & $D F_{7}$ & 99 & 84 & 8 & 67 & 34 & 92 & 89 & 84 & 77 & 16 & 70 & 127 & 65 & $\mathrm{Y}$ \\
\hline & $D F_{8}$ & 63 & 41 & 63 & 66 & 34 & 33 & 16 & 56 & 37 & 96 & 45 & 78 & 33 & $\mathrm{Y}$ \\
\hline & $D F_{9}$ & 72 & 35 & 74 & 85 & 23 & 74 & 49 & 84 & 9 & 23 & 56 & 109 & 54 & $\mathrm{Y}$ \\
\hline & $D F_{10}$ & 47 & 27 & 2 & 35 & 15 & 15 & 35 & 2 & 63 & 38 & 27 & 65 & 28 & \\
\hline & $D F_{11}$ & 34 & 10 & 40 & 38 & 22 & 56 & 68 & 15 & 7 & 98 & 32 & 72 & 14 & $\mathrm{Y}$ \\
\hline & $D F_{12}$ & 89 & 68 & 18 & 75 & 97 & 18 & 73 & 8 & 21 & 20 & 52 & 118 & 55 & $\mathrm{Y}$ \\
\hline & $D F_{13}$ & 99 & 98 & 24 & 10 & 4 & 15 & 64 & 83 & 12 & 19 & 45 & 121 & 54 & $\mathrm{Y}$ \\
\hline & $D F_{14}$ & 78 & 97 & 92 & 78 & 71 & 43 & 33 & 61 & 40 & 68 & 66 & 109 & 67 & \\
\hline & $D F_{15}$ & 31 & 75 & 10 & 27 & 31 & 99 & 82 & 22 & 43 & 87 & 47 & 105 & 43 & \\
\hline & $D F_{16}$ & 17 & 34 & 33 & 2 & 87 & 46 & 69 & 53 & 71 & 88 & 46 & 97 & 44 & \\
\hline & $D F_{17}$ & 57 & 55 & 29 & 66 & 66 & 88 & 84 & 18 & 15 & 92 & 53 & 104 & 47 & \\
\hline & $D F_{18}$ & 37 & 25 & 95 & 31 & 61 & 9 & 85 & 33 & 73 & 22 & 50 & 106 & 48 & $\mathrm{Y}$ \\
\hline & $D F_{19}$ & 85 & 99 & 29 & 24 & 68 & 50 & 84 & 32 & 40 & 3 & 57 & 109 & 51 & $\mathrm{Y}$ \\
\hline & $D F_{20}$ & 7 & 84 & 62 & 61 & 39 & 90 & 97 & 40 & 15 & 1 & 55 & 116 & 53 & $\mathrm{Y}$ \\
\hline & $D F_{21}$ & 47 & 36 & 93 & 98 & 27 & 34 & 49 & 21 & 36 & 4 & 49 & 101 & 42 & $\mathrm{Y}$ \\
\hline
\end{tabular}


Table 8 Results of the performance evaluation of the proposed consumer demands analysis method

\begin{tabular}{|c|c|c|c|c|c|c|}
\hline \multirow[t]{2}{*}{ Questionnaire item } & \multicolumn{2}{|c|}{ Control group } & \multicolumn{2}{|c|}{$\begin{array}{l}\text { Experimental } \\
\text { group }\end{array}$} & \multirow[t]{2}{*}{$T$} & \multirow[t]{2}{*}{$P$} \\
\hline & Mean & S.D. & Mean & S.D. & & \\
\hline $\begin{array}{l}\text { 1. The analytical range of the consumer demands } \\
\text { analysis is very wide. }\end{array}$ & 3.1 & 0.851 & 3.566 & 0.874 & -1.945 & $* 0.028$ \\
\hline $\begin{array}{l}\text { 2. The consumer demands analysis reduced the time } \\
\text { needed for market planning. }\end{array}$ & 3 & 0.827 & 3.466 & 0.74 & -2.041 & $* 0.022$ \\
\hline $\begin{array}{l}\text { 3. The consumer demands analysis can be used to } \\
\text { analyze information about market changes. }\end{array}$ & 3.133 & 1.016 & 3.633 & 0.722 & -2.076 & $* 0.021$ \\
\hline $\begin{array}{l}\text { 4. The consumer demands analysis does not require } \\
\text { any training or expertise. }\end{array}$ & 2.966 & 0.929 & 3.5 & 0.81 & -2.214 & $* 0.015$ \\
\hline $\begin{array}{l}\text { 5. The data sources for the consumer demands } \\
\text { analysis are reliable. }\end{array}$ & 3 & 0.689 & 3.666 & 0.85 & -2.942 & $* * 0.002$ \\
\hline $\begin{array}{l}\text { 6. The analytical results of the consumer demands } \\
\text { analysis are objective. }\end{array}$ & 3.066 & 1.167 & 3.566 & 0.874 & -1.916 & $* 0.03$ \\
\hline 7. The consumer demands analysis is effective. & 3.333 & 1.54 & 3.433 & 0.46 & -0.387 & 0.35 \\
\hline
\end{tabular}

$*: p$ value $<0.05$ indicates significance at $0.05 * *: p$ value $<0.01$ indicates significance at 0.01 this study, they had all been working for at least 15 years, and were all company leaders or experts in their line of business. Therefore, the results derived from their opinions could be said to have expert validity.

The results of the analysis are shown in Table 8. The responses to questionnaire items 1 to 6 indicate that the method proposed in this work could be seen as effective. The results also indicated that the mechanism can be used to retrieve reliable information about a changing market and consumers. The results of the eWOM analysis on consumer demands can be seen as both objective and reliable, and so useful for market planning. This study also interviewed the participants, and they stated that one of the benefits of the method was that it provided timely and extensive consumer information, which is less likely to be obtained with traditional questionnaire surveys. The analytical results for questionnaire item 7 were not significant. The participants agreed that this study presented a new analytical method to analyze consumer demands. While verifying the application and value of this method requires long-term study, many participants thought that eWOM analysis may be what the business world wants, and that the analytical results of this study might be able to help enterprises to innovate and improve their products or services.

In summary, the results of analyzing the questionnaire indicate that the method proposed in this study is better than traditional questionnaire surveys. It may thus be able to offer timely and extensive analytical results that help managers make better decisions. However, many participants thought that the method still requires long-term analyses and observations to verify its reliability. A short-term study was carried out in this worked because we wanted to find out any problems with this approach and then work to address them. As such, future studies are needed to extend the work of the current project.

\section{Conclusions and perspectives}

A computer-based approach was developed in this study to analyze consumer demands, and this can help enterprises develop their product lines and improve their services. This work provides primary findings and has the following contributions to the literature. First, a user satisfaction survey was conducted to reveal the effectiveness of this system, and the results prove that it is capable of analyzing consumer demands, as well as providing marketers and managers with valuable market information. Secondly, a computer-based approach was developed in this study to improve traditional methods of analyzing consumer demands. Finally, this paper employed computer programs to analyze critical consumer demands. Computerized analysis makes it easier for enterprises to collect and analyze this kind of data, while enhancing the accuracy of the process.

Based on the computer-based approach presented in this work, this study has three suggestions for future works. First and foremost, future studies should include processes to filter out eWOM information published by enterprises in order to increase the validity of the results. Secondly, this study used a questionnaire with marketers and managers for the purpose of system evaluation and to identify potential issues for future enhancement. However, the evaluation process should be continued for at least three to five years for more objective results. Therefore, a longitudinal study is suggested to determine the feasibility of this mechanism. Finally, the system presented in this study can only determine consumer demands valued by 
eWOM, and is not capable of prioritizing which consumer demands deserve more improvement efforts. As a result, future studies are suggested to take a step further in designing a computer-based approach that could prioritize the items that require the most attention.

Acknowledgments The authors would like to thank the National Science Council of the Republic of China, Taiwan, for partially supporting this research under Contract Nos. NSC 100-2221-E-006208-MY3.

Open Access This article is distributed under the terms of the Creative Commons Attribution 4.0 International License (http:// creativecommons.org/licenses/by/4.0/), which permits unrestricted use, distribution, and reproduction in any medium, provided you give appropriate credit to the original author(s) and the source, provide a link to the Creative Commons license, and indicate if changes were made.

\section{References}

Archak, N., Ghose, A., \& Ipeirotis, P. G. (2011). Deriving the Pricing Power of Product Features by Mining Consumer Reviews. Management Science, 57(8), 1485-1509.

Bai, B., Law, R., \& Wen, I. (2008). The Impact of Website Quality on Customer Satisfaction and Purchase Intentions: Evidence from Chinese Online Visitors. International Journal of Hospitality Management, 27(3), 391-402.

Bei, L. T., \& Shang, C. F. (2006). Building Marketing Strategies for StateOwned Enterprises against Private Ones Based on the Perspectives of Customer Satisfaction and Service Quality. Journal of Retailing and Consumer Services, 13(1), 1-13.

Chen, Y. J., \& Chen, Y. M. (2012). Knowledge Evolution Course Discovery in a Professional Virtual Community. Knowledge-Based Systems, 33(1), 1-28.

Chen, C. W. D., \& Cheng, C. Y. J. (2009). Understanding Consumer Intention in Online Shopping: A Respecification and Validation of the Delone and Mclean Model. Behaviour \& Information Technology, 28(4), 335-345.

Chen, Y. L., Tang, K., Wu, C. C., \& Jheng, R. Y. (2014). Predicting the influence of users' posted information for eWOM advertising in social networks. Electronic Commerce Research and Applications, 13(6), 431-439.

Chen, T. Y., Liu, Y. C., \& Chen, Y. M. (2016). A method of potential customer searching from opinions of network villagers in virtual communities. Online Information Review, 40(1), 146-167.

Choi, H., \& Varian, H. (2012). Predicting the present with google trends. Economic Record, 88(Supplement S1), 2-9.

Choi, J. Y., Shin, J., \& Lee, J. (2011). Strategic Demand Forecasts for the Tablet Pc Market Using the Bayesian Mixed Logit Model and Market Share Simulations. Online publication. Behaviour \& Information Technology, 32(11), 1177-1190.

Chu, S. C., \& Sung, Y. (2015). Using a consumer socialization framework to understand electronic word-of-mouth (eWOM) group membership among brand followers on Twitter. Electronic Commerce Research and Applications, 14(4), 251-260.

Currie, J., DellaVigna S., Moretti, E., Pathania, V. (2010). The effect of fast-food restaurants on obesity and weight gain. American Economic Journals: Economic Policy, 2, 32-63.

Deng, Z., Lu, Y., Wei, K. K., \& Zhang, J. (2010). Understanding Customer Satisfaction and Loyalty: An Empirical Study of Mobile Instant Messages in China. International Journal of Information Management, 30(4), 289-300.
Earle, M. (1997). Innovation in the Food Industry. Trends in Food Science \& Technology, 8(4), 166-175.

Erkan, I., \& Evans, C. (2016). The influence of eWOM in social media on consumers' purchase intentions: An extended approach to information adoption. Computers in Human Behavior, 61(1), 47-55.

Fan, T. K., \& Chang, C. H. (2010). Sentiment-Oriented Contextual Advertising. Knowledge and Information Systems, 23(3), 321-344.

Feng, S., Wang, D., Yu, G., Gao, W., \& Wong, K. F. (2011). Extracting Common Emotions from Blogs Based on Fine-Grained Sentiment Clustering. Knowledge and Information Systems, 27(2), 281-302.

French, S. A., Harnack, L., \& Jeffery, R. W. (2000). Fast Food Restaurant Use among Women in the Pound of Prevention Study: Dietary, Behavioral and Demographic Correlates. International journal of obesity and related metabolic disorders: journal of the International Association for the Study of Obesity, 24(10), 13531359.

Grigoroudis, E., \& Siskos, Y. (2004). A Survey of Customer Satisfaction Barometers: Some Results from the TransportationCommunications Sector. European Journal of Operational Research, 52(2), 334-353.

He, Y., \& Zhou, D. (2011). Self-Training from Labeled Features for Sentiment Analysis. Information Processing \& Management, 47(4), 606-616.

Hennig-Thurau, T., \& Walsh, G. (2003). Electronic Word-of-Mouth: Motives for and Consequences of Reading Customer Articulations on the Internet. International Journal of Electronic Commerce, 8(2), 51-74.

Jiménez-Jiménez, D., \& Cegarra-Navarro, J. G. (2007). The Performance Effect of Organizational Learning and Market Orientation. Industrial Marketing Management, 36(6), 694-708.

Kim, A. J., \& Johnson, K. K. P. (2016). Power of consumers using social media: examining the influences of brand-related user-generated content on Facebook. Computers in Human Behavior, 58(1), 98108.

Kim, M. K., Park, M. C., \& Jeong, D. H. (2004). The Effects of Customer Satisfaction and Switching Barrier on Customer Loyalty in Korean Mobile Telecommunication Services. Telecommunications Policy, 28(2), 145-160.

Kivela, J., Inbakaran, R., \& Reece, J. (1999). Consumer Research in the Restaurant Environment, Part 1: A Conceptual Model of Dining Satisfaction and Return Patronage. International Journal of Contemporary Hospitality Management, 11(5), 205-222.

Kotler, P., \& Fox, K.F.A. (1995). Strategic marketing for educational institutions, 2rd ed., Prentice-Hall.

Ku, L. W., Wu, T. H., Lee, L. Y., Chen, H. H. (2005). Construction of an Evaluation Corpus for Opinion Extraction. In Proceedings of the NTCIR-5 Workshop, (pp.513-520). Tokyo, Japan.

Kuo, Y. F., Wu, C. M., \& Deng, W. J. (2009). The Relationships among Service Quality, Perceived Value, Customer Satisfaction, and PostPurchase Intention in Mobile Value-Added Services. Computers in Human Behavior, 25(4), 887-896.

Kwon, S. H., Cha, M. H., \& Kim, Y. K. (2005). High School Students' Satisfaction with Foodservice Quality Is Affected by Foodservice Management Type. Journal of Food Science and Nutrition, 10(4), 372-377.

Lee, M., \& Ulgado, F. M. (1997). Consumer Evaluations of Fast-Food Services: A Cross-National Comparison. Journal of Services Marketing, 11(1), 39-52.

Li, S. T., \& Chang, W. C. (2009). Exploiting and transferring presentational knowledge assets in R\&D organizations. Expert Systems with Applications, 36(1), 766-777.

Liu, Y., \& Jang, S. C. S. (2009). Perceptions of Chinese Restaurants in the Us: What Affects Customer Satisfaction and Behavioral Intentions? International Journal of Hospitality Management, 28(3), 338-348.

Nieto, J., Hernández-Maestro, R. M., \& Muños-Gallego, P. A. (2014). Marketing decisions, customer reviews, and business performance: 
The use of the Toprural website by Spanish rural lodging establishments. Tourism Management, 45(1), 115-123.

Pai, M. Y., Chu, H. C., Wang, S. C., \& Chen, Y. M. (2013a). Electronic word of mouth analysis for service experience. Expert Systems with Applications, 40(6), 1993-2006.

Pai, M. Y., Chu, H. C., Wang, S. C., \& Chen, Y. M. (2013b). Ontologybased SWOT analysis method for electronic word-of-mouth. Knowledge-Based Systems, 50, 134-150.

Park, C. (2004). Efficient or Enjoyable? Consumer Values of Eating-out and Fast Food Restaurant Consumption in Korea. International Journal of Hospitality Management, 23(1), 87-94.

Park, D. H., \& Lee, J. (2009). Ewom Overload and Its Effect on Consumer Behavioral Intention Depending on Consumer Involvement. Electronic Commerce Research and Applications, 7(4), 386-398.

Peter, N. (1999). When windows replace walls: Investigating virtual word of mouth exchanges and constructing multilogue profile. Advances in Consumer Research, 26(1), 653-654.

Preis, T., Moat, H. S., and Eugene Stanley H. (2013), Quantifying Trading Behavior in Financial Markets Using Google Trends,
Scientific Reports, http://www.nature.com/srep/2013/130425/ srep01684/full/srep01684.html.

Rowley, J. (2007). The wisdom hierarchy: representations of the DIKW hierarchy. Journal of Information Science, 33(2), 163-180.

Söderlund, M., \& Rosengren, S. (2007). Receiving Word-of-Mouth from the Service Customer: An Emotion-Based Effectiveness Assessment. Journal of Retailing and Consumer Services, 14(2), 123-136.

Vechtomova, O. (2010). Facet-Based Opinion Retrieval from Blogs. Information Processing \& Management, 46(1), 71-88.

Walstad, W. B., \& Rebeck, K. (2002). Assessing the Economic Knowledge and Economic Opinions of Adults. The Quarterly Review of Economics and Finance, 42(5), 921-935.

Watson, H. J., \& Wixom, B. H. (2007). The Current State of Business Intelligence. Computer, 40(9), 96-99.

Wu, T. Y., \& Lin, C. A. (2017). Predicting the effects of eWOM and online brand messaging: Source trust, bandwagon effect and innovation adoption factors. Telematics and Informatics, 34(2), 470480 .

Ziethmal, V. A., \& Bitner, M. J. (2003). Service Marketing: Integrating Customer Focus across the Firm, 3rd ed., McGraw-Hill. 